\title{
As pediatric trials go global, some worry who really benefits
}

Although children suffer from many of the same diseases as adults and are often treated with the same drugs, only a small fraction of approved medicines is ever tested in pediatric clinical trials. To encourage more safety and efficacy studies of drugs in children, in 1997 the US Food and Drug Administration (FDA) created a special provision that grants six-month patent extensions to medicines screened in children.

Dubbed the Pediatric Exclusivity Provision, the licensing status has led to more than 150 drugs now being approved for specific use in children. But with an increasing number of pediatric trials being conducted in countries where the resulting medicines often aren't even available, some critics say the provision pads the pockets of 'big pharma' more than it benefits youngsters.

"The incentive is to perform the study the fastest way possible and the cheapest way possible," says Sara Pasquali, a pediatrician at Duke University School of Medicine in

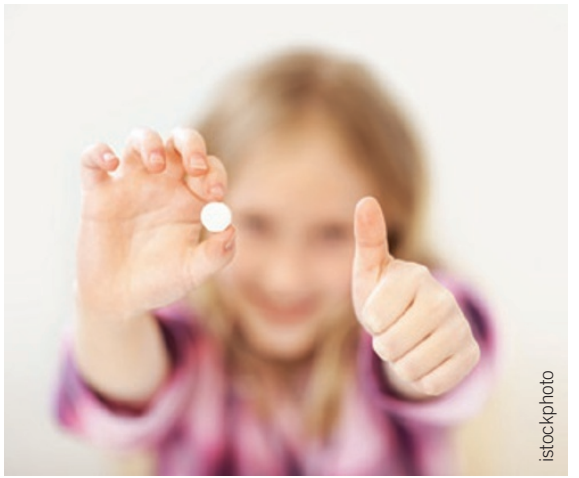

Growing options: Trials target kids.
Durham, North Carolina. "It's much cheaper to conduct a study overseas than in the US."

To reveal the extent of globalization, Pasquali and her colleagues surveyed where around the world drug companies and researchers held their trials for pediatric exclusivity. Reporting last month, they found that $65 \%$ of all 174 such trials involved centers located in at least one country outside the US, close to $40 \%$ enrolled participants in developing nations and around $10 \%$ did not include any sites in the US (Pediatrics 126, e687-692, 2010).

\section{Developing concerns}

Although a similar march toward globalization has already been documented in adult clinical research, conducting trials on children in poor countries presents some unique challenges.

The issue of informed consent and possible coercion is especially tricky in children for whom an adult is providing the consent, says David Reith, a pediatrician at the Dunedin School of Medicine in New Zealand who has studied the impact of the measure. Monetary incentives to enroll in a study can be substantial-sometimes exceeding a family's income-and frequently benefit the adult providing the consent, rather than the child, he adds. "These are issues that should be dealt with by institutional ethics committees," Reith says. But that infrastructure is often lacking in developing countries.

Although not yet systematically studied, the picture is probably similar for pediatric clinical trials registered in the EU, which enacted a similar provision in 2007 granting extended market exclusivity for drugs tested in children. But since the European policy requires pharmaceutical companies to present their data earlier on in the regulatory process, regulators may have more time to ensure that the specific therapeutic needs of children are met, says Rosalind Smyth, director of clinical research at the University of Liverpool and chair of the UK Commission on Human Medicines' Paediatric Medicines Expert Advisory Group.

Even with the ethical concerns, Smyth defends the need to go abroad for pediatric trials. "A number of [pediatric] conditions are quite rare, so you're not going to complete the study within a reasonable time frame unless you move outside the country," she says. But, with few obvious benefits to the children in the places where drugs are tested, some critics charge that drug companies have really been the sole beneficiaries of the FDA incentive.

However, Reith notes that companies don't always win out from the provision. "Some companies have lost money, whereas others have made an enormous amount of profit" testing medicine in children, he says, because costs for conducting pediatric clinical trials, which are typically higher than for adult trials, sometimes exceed what the company makes on sales. Indeed, a 2007 study found that net profits from drugs specifically tested in children ranged from over $\$ 500$ million to losses of nearly $\$ 9$ million, with drugs that were blockbusters in adults more likely to yield larger profits (J. Am. Med. Assoc. 297, 480-488, 2007).

Monica Heger

\section{Companies hope to bring DNA storage in from the cold}

Would scientists willingly junk their fridges, given the chance? Some companies hope their new methods of storing dried genetic material at room temperature will convince researchers to do exactly that. But, for such ventures to succeed, the firms must convince biologists to abandon simpler storage methods.

"The storage formats we use have been in use for over 50 years. Any new method would need to be compact, simple to implement, not require significant infrastructure or financial investment, and would allow repeated sampling of materials," says Kevin McCluskey, curator of the Fungal Genetics Stock Center in Kansas City, Missouri.

Scientists often dry samples for storage using standard Whatman filter paper. The procedure is quite simple: add the sample onto the filter paper, let it dry, and then wrap it in sterile tinfoil.

According to Mike Hogan, chief scientific officer for the Carlsbad, California-based company GenVault, treated filter paper is perfectly fine for storing small plasmid DNA. But he adds that it's not ideal for long-term storage of air-dried purified DNA or for use with DNA samples with higher molecular weights.

GenVault has developed a new type of filter paper treated with a chemical dubbed GenTegra that rapidly dissolves when the sample is rehydrated for further study "so that there [is] no possibility of DNA 'sticking' to-and hence being contaminated by - the filter paper support," Hogan says.

Meanwhile, Biomatrica, a San Diegobased company, offers a glass polymer that 'shrink-wraps' genetic material, 